Comparison of axillary, oral, and forehead temperature

\author{
J E MASTERS \\ Department of Paediatrics, Guy's Hospital Medical School, London
}

SUMMARY The forehead Fever Scan gave a better estimate of oral temperature than did axillary temperature in 36 children with and without fever.

It is generally accepted that in the first year of life the temperature should be taken rectally, up to age 5 it should be taken in the axilla, and in schoolchildren it should be taken orally. ${ }^{1}$ The groin has also been suggested as a useful site in infancy. ${ }^{2}$ Normal oral temperature is considered to be $98 \cdot 6^{\circ} \mathrm{F}$ $\left(37^{\circ} \mathrm{C}\right)$ but it fluctuates throughout the day. In this study, as in others, ${ }^{3}$ fever was defined as an oral temperature $\geqslant 100^{\circ} \mathrm{F}\left(37 \cdot 7^{\circ} \mathrm{C}\right)$. No definition of fever as measured in the axilla is quoted in standard nursing or medical textbooks.

The forehead Fever Scan is one method of temperature measurement. It consists of plasticencased thermophototropic substances that change colour over a specific short range of temperature. The manufacturers recommend that if readings are in the range $102-104^{\circ} \mathrm{F}\left(38 \cdot 8-40^{\circ} \mathrm{C}\right)$, or if one suspects that fever is present, a doctor should be consulted.

Another type of thermometer is the Nicholas Temtake oral disposable thermometer, which uses a series of temperature-sensitive dots that turn blue to give a reading. In a recent survey ${ }^{4}$ some of these thermometers occasionally failed to register and others were chewed beyond useful recognition. The method was expensive compared with the ordinary clinical thermometer although reasonably accurate results were obtained and it was considered to be useful if cross-infection was a problem.

This study aimed to compare the accuracy of axillary temperature and the Fever Scan as indicators of the core temperature measured in the mouth.

\section{Methods}

36 children aged between 5 and 15 years were studied at seven hospitals, one general practice, and a primary school. Healthy children were tested and also those in hospital with conditions ranging from postoperative pyrexia to possible Still's disease and hypothalamic malfunction. All the children were over age 5 years as it was important that they should be able to tolerate an oral thermometer. The three thermometers were used simultaneously within 3 minutes.

Electronic thermometer-orally. The electrotherm digital thermometer (Marshall Electronics, Inc.) is a battery-operated electronic thermometer with a digital readout. It has disposable probe covers to prevent cross-infection. It was wiped with a mediswab, a cover was applied, and it was then placed sublingually for 1 minute. The readout was in ${ }^{\circ} \mathrm{F}$.

Clinical thermometer-axillary. The clinical thermometer used was one that had been tested by the British Standards Institution; it is made for Boots by Zeal (England). The thermometer was wiped with a mediswab and placed under the arm for 3 minutes. This time was chosen because it had been shown in a study from Oxford ${ }^{5}$ that at least 3 minutes should be allowed when recording oral temperatures. The results were in ${ }^{\circ} \mathrm{F}$.

Fever Scan-forehead. The Fever Scan (American Thermometer Co.) is a forehead thermometer which quickly estimates body temperature. The forehead was wiped with a tissue and the scan held at both ends and pressed flush against the forehead for 15 seconds. The scan was then read immediately. The section in which the colour green appeared gave the correct temperature. Tan/red was $1^{\circ} \mathrm{F}$ lower than the number shown so that the scan can read from 96 to $104^{\circ} \mathrm{F}\left(35 \cdot 5-40^{\circ} \mathrm{C}\right)$. The scan was wiped with a mediswab after use.

\section{Results}

The children had oral temperatures from 95.9 to $102 \cdot 5^{\circ} \mathrm{F}\left(35 \cdot 5\right.$ to $\left.39^{\circ} \mathrm{C}\right)$, scan readings from 97 to $103^{\circ} \mathrm{F}\left(36.1\right.$ to $\left.39 \cdot 4^{\circ} \mathrm{C}\right)$, and axillary temperatures ranging from 96 to $101 \cdot 4^{\circ} \mathrm{F}\left(35 \cdot 5\right.$ to $\left.38 \cdot 5^{\circ} \mathrm{C}\right)$.

The regression of Fever Scan temperature against oral temperature gave a correlation coefficient of $0 \cdot 86$ (Fig. 1a). The regression of axillary temperature against oral temperature gave a correlation coefficient of 0.81 (Fig. 1b). The line $y=x$ reflects oral temperature equivalent to the axillary or scan temperature. A $t$ test between $\mathrm{y}=\mathrm{x}$ and the two regression lines showed that there was no significant 


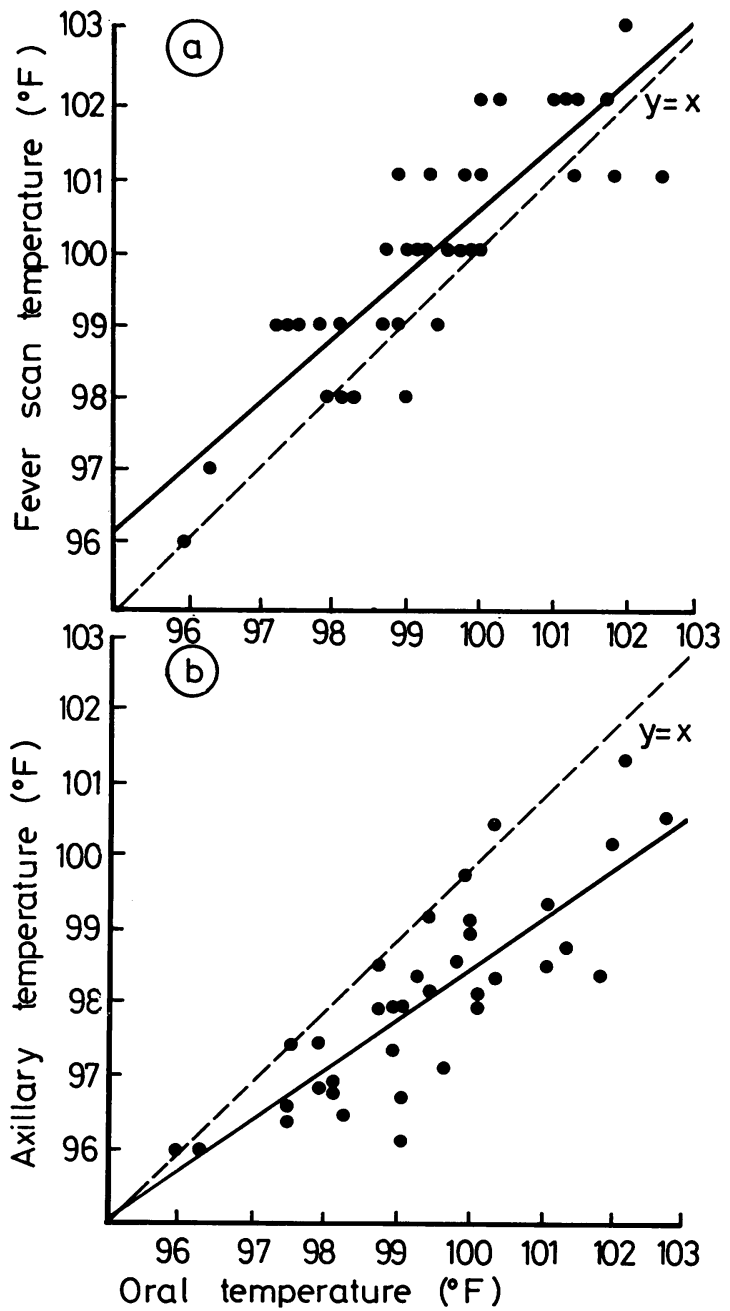

Figure Scatter diagrams and regression lines comparing (a) Fever Scan and (b) axillary recordings with oral temperature. Each regression line is compared with the line $y=x$.

difference $(P>0 \cdot 1)$ between $y=x$ and the regression line of scan against oral temperature. This suggests that the Fever Scan gave a reasonable estimate of oral temperature. There was however a significant difference $(P<0 \cdot 01)$ between $y=x$ and the regression line of axillary against oral temperature, suggesting that axillary temperature did not give a good estimate of oral temperature.

The Table shows the number of fevers, defined as $\geqslant 100^{\circ} \mathrm{F}\left(37^{\circ} 7^{\circ} \mathrm{C}\right)$ orally, that were recognised by the Fever Scan. A reading $\geqslant 101^{\circ} \mathrm{F}\left(38 \cdot 3^{\circ} \mathrm{C}\right)$
Table Comparison of oral measurement with Fever Scan

\begin{tabular}{llll}
\hline & \multicolumn{3}{l}{ Oral temperature $\left({ }^{\circ} \mathrm{F}\right)$} \\
\cline { 2 - 4 } Scan temperature $\left({ }^{\circ} \mathrm{F}\right)$ & $\begin{array}{l}\text { Fever } \\
(>106)\end{array}$ & No fever & Total \\
\hline Fever $(>101)$ & 10 & 3 & 13 \\
No fever & 1 & 22 & 23 \\
Total & 11 & 25 & 36 \\
\hline
\end{tabular}

on the Fever Scan produced 3 false-positives and 1 false-negative fever-that is, it recognised $10 / 11(91 \%)$ of the fevers. With a threshold at $\geqslant 100^{\circ} \mathrm{F}$ the number of false-positives was considerably increased.

The results of the axillary thermometers produced more false-negative fevers and, with fever defined as an axillary temperature $\geqslant 99^{\circ} \mathrm{F}\left(37 \cdot 7^{\circ} \mathrm{C}\right)$ to allow for temperature difference between the sublingual pocket and axilla, 6/11 (55\%) of the fevers as defined by an oral temperature $\geqslant 100^{\circ} \mathrm{F}\left(37 \cdot 7^{\circ} \mathrm{C}\right)$ were not identified.

\section{Discussion}

The Fever Scan appears to provide a better estimate of oral temperature than does axillary temperature in schoolchildren.

It is possible that the Fever Scan would be a satisfactory method of taking temperatures in the under 5 age group if fever is taken as $\geqslant 101^{\circ} \mathrm{F}$ $\left(38 \cdot 3^{\circ} \mathrm{C}\right)$ on the scan. Further studies would be needed to confirm this statistically with this value already decided on.

These results differ from those obtained in another study, ${ }^{3}$ which compared temperatures measured by a Clinitemp forehead scan with temperatures measured rectally (pyrexia $\geqslant 101^{\circ} \mathrm{F}$ ) and orally (pyrexia $\geqslant 100^{\circ} \mathrm{F}$ ) by an electronic thermometer. Those results gave an unacceptable rate of falsenegative values: $17(57 \%)$ of 30 children with fever had normal temperatures with the Clinitemp $\left(\geqslant 100^{\circ} \mathrm{F}\right)$. If the threshold had been raised to $\geqslant 101^{\circ} \mathrm{F}$ more false-negatives would have been obtained.

I thank Rosemary Dalton, Department of Community Medicine, Guy's Hospital, and the staff, parents, and children for their co-operation and help.

\section{References}

1 Meadow S R, Smithells R W. Lecture notes on paediatrics, third edition. Oxford: Blackwell Scientific, 1978. 
2 Macleod J G. Clinical examination, third edition. Edinburgh: Churchill Livingstone, 1974.

3 Reisenger K, Kao J, Grant D. Inaccuracy of the Clinitemp skin thermometer. Pediatrics $1979 ; 64: 4-6$.

4 Moorat D. The cost of taking temperatures. Nursing Times 1976, 72: 767-70.
5 Coggon D N M, Vessey M P. Errors in using clinical thermometers. Br Med J 1976; i: 692.

Correspondence to $\mathrm{Mr} \mathrm{J}$ E Masters, Medical Student, Department of Paediatrics, Guy's Hospital Medical School, St Thomas Street, London SE1 9RT.

\title{
Does discarding the first few millilitres of breast milk improve the bacteriological quality of bank breast milk?
}

\author{
L CARROLL, M OSMAN, AND D P DAVIES
}

Department of Child Health and Microbiology, Leicester Royal Infirmary

SUMMARY The bacteriology of 20 paired samples of breast milk was analysed to find out if discarding the first few millilitres would reduce the amount of bacterial contamination in breast milk donated to a hospital milk bank. The first sample was the initial 2-3 ml collected from the opposite breast to that first suckled by the baby, and the second was a midstream sample from the same breast. There was no significant difference in the colony counts between the paired samples, and in no instance did the bacterial flora of the second sample differ from that of the first.

In collecting breast milk for human milk banks an important practical question that is often asked, does discarding the initial few millilitres of milk before the definitive collection begins yield a bacteriologically clearer milk ${ }^{1}$ Williamson et al., ${ }^{2}$ referring to the work of West and Hewitt, ${ }^{3}$ proposed that mothers should discard the first 5-10 ml. This might be appropriate for milk banks that rely mainly on milk collected from mothers at home when lactation is well established. However, many milk banks, of which ours is an example, generally use milk which is collected from early lactating mothers who are still in hospital. In such circumstances discarding the first few millilitres would greatly reduce the amount of milk available for babies.

\section{Materials and methods}

The milk bank of the Leicester Royal Infirmary Maternity Hospital is mainly stocked from milk which drips from the opposite breast during lactation and collected in a shell. In this study two samples of breast milk were collected from 20 mothers berween 4 and 7 days after delivery: the first sample was the initial 2-3 $\mathrm{ml}$ which were collected from the opposite breast to that first suckled by the baby; the second was a midstream sample from the same breast. Each milk sample was

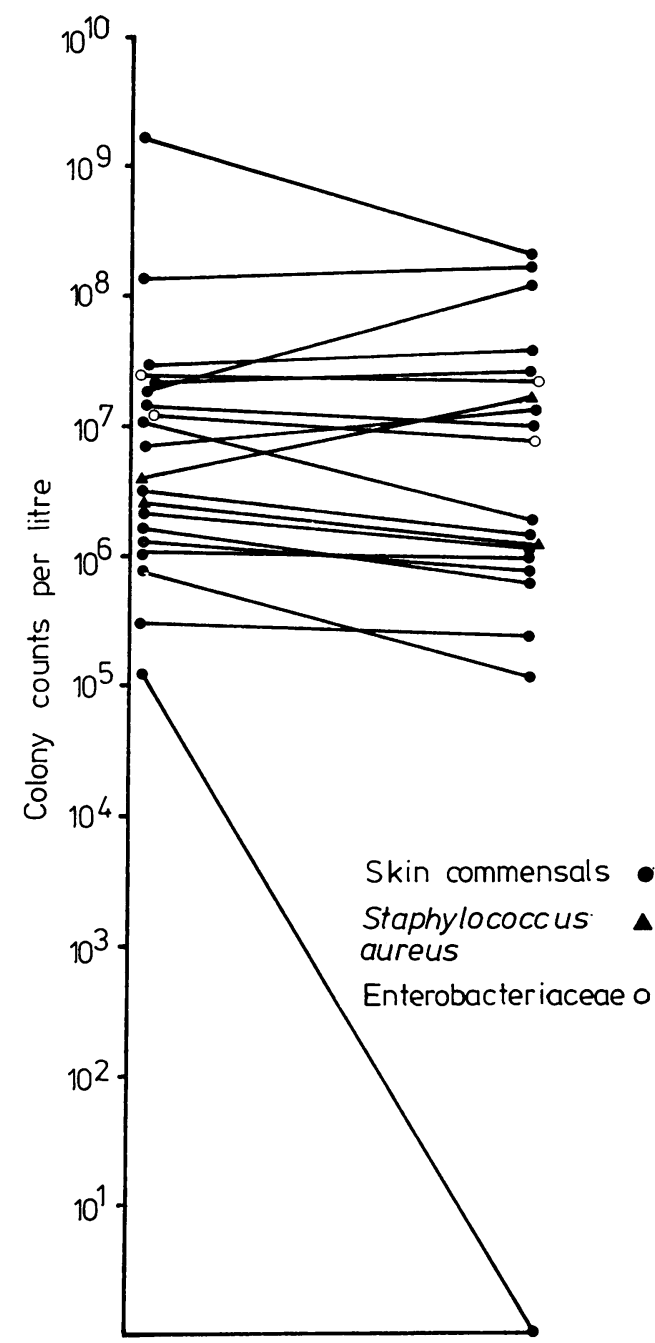

Initial 2-3ml milk Midstream milk

Figure Bacterial colony counts in 20 paired samples of donated breast milk. 